\title{
O gênero Buddleja (Scrophulariaceae) no estado do Paraná, Brasil
}

\author{
The genus Buddleja (Scrophulariaceae) in the state of Paraná, Brazil
}

\author{
Laura Calderan de Lannoy ${ }^{1,4}$, Lucas Katsumi Rocha Hinoshita ${ }^{1}$, \\ Guilherme Peres Coelho ${ }^{2}$ \& Renato Goldenberg ${ }^{3}$
}

\begin{abstract}
Resumo
O gênero Buddleja apresenta dez espécies e duas subespécies no Paraná, das quais uma espécie é cultivada, e as demais nativas: Buddleja brachiata, B. cuneata, B. davidii (cultivada), B. elegans (B. elegans subsp. elegans e B. elegans subsp. angustata), B. grandiflora, B. hatschbachii, B. oblonga, B. ramboi (nova ocorrência para o estado), B. stachyoides e B. thyrsoides. O presente tratamento taxonômico apresenta chave de identificação, descrições, ilustrações e mapas de distribuição para cada táxon.
\end{abstract}

Palavras-chave: Buddlejaceae, flora, Loganiaceae, taxonomia.

\begin{abstract}
The genus Buddleja has ten species and two subspecies in Paraná, from which one species is cultivated, and the others native: Buddleja brachiata, B. cuneata, B. davidii (cultivated), B. elegans (B. elegans subsp. elegans and B. elegans subsp. angustata), B. grandiflora, B. hatschbachii, B. oblonga, B. ramboi (new record for the state), B. stachyoides and B. thyrsoides. In this taxonomic treatment we present an identification keys, descriptions, illustrations and distribution maps for each taxon.
\end{abstract}

Key words: Buddlejaceae, flora, Loganiaceae, taxonomy.

\section{Introdução}

A família Scrophulariaceae Juss. (Lamiales) possui distribuição ampla, sendo encontrada em regiões temperadas a tropicais do globo, com 59 gêneros e cerca de 1.880 espécies (APG IV 2016; Souza \& Giulietti 2009; Stevens 2001). No Brasil ocorrem apenas cinco gêneros: Alonsoa Ruiz \& Pav., Ameroglossum Eb.Fisch., S.Vogel \& A.V.Lopes, Buddleja L., Scrophularia L. e Verbascum L. (BFG 2015), embora Capraria L., Diascia Link \& Otto, Leucophyllum Bonpl., Limosella L., Myoporum Sol. ex G.Forst., Nemesia Vent. e Sutera Roth tenham sido também citados para o país (Souza \& Lorenzi 2012). Para o Paraná há informações conflitantes: BFG (2015) menciona Buddleja, Scrophularia e Verbascum, enquanto Kaehler (2014) cita apenas Buddleja e Verbascum.
Buddleja é o único gênero de Scrophulariaceae nativo do Paraná, e também o que possui maior número de registros para o estado.

$\mathrm{O}$ gênero Buddleja foi descrito como parte de Scrophulariaceae (Jussieu 1789) e posteriormente foi transferido para Loganiaceae R.Br. ex Mart. (Bentham \& Hooker 1876). No início do século $\mathrm{XX}$, sua posição taxonômica foi novamente alterada, passando a ser reconhecido como uma família à parte, Buddlejaceae K.Wilh., juntamente com outros sete gêneros (Wilhelm 1910 apud Norman 2000). No final do século XX, a partir de análises filogenéticas baseadas em sequências de DNA, a família Scrophulariaceae s.l., como era tradicionalmente circunscrita, foi apontada como polifilética e desmembrada; parte da família permaneceu em clado atualmente aceito como

\footnotetext{
${ }^{1}$ Universidade Federal do Paraná, Setor de Ciências Biológicas, Pós-graduação em Botânica, Av. Cel. Francisco H. dos Santos s/n, Jardim das Américas, 81531970, Curitiba, PR, Brasil.

${ }^{2}$ Universidade Federal do Rio Grande do Sul, Inst. Biociências, Depto. Botânica, Av. Bento Gonçalves 9500, Agronomia, 91509-900, Porto Alegre, RS, Brasil.

${ }^{3}$ Universidade Federal do Paraná, Setor de Ciências Biológicas, Depto. Botânica, Av. Cel. Francisco H. dos Santos s/n, Jardim das Américas, 81531-970, Curitiba, PR, Brasil.

${ }^{4}$ Autor para correspondência: lauradelannoy@gmail.com
} 
Scrophulariaceae s.s. (Olmstead \& Reeves 1995; Olmstead et al. 2001; Oxelman et al. 1999, 2005). A partir destas análises e, pouco depois, com a adição de dados morfológicos (Bremer et al. 2002), o gênero Buddleja foi incluído novamente entre as Scrophulariaceae (APG II 2003). Estudos filogenéticos recentes mostram que Buddleja é parafilético, e que apenas com a inclusão de Chilianthus Burch., Emorya Torr., Nicodemia Ten. e provavelmente Gomphostigma Turcz constituirá um grupo monofilético (Chau et al. 2017).

O gênero Buddleja ocorre no continente americano (desde o oeste dos Estados Unidos até o sul do Chile e Argentina), Ásia e África (Ferreira \& Martins 2005), com aproximadamente 100 espécies (BFG 2015). No Brasil é representado por 14 espécies, encontradas nos estados de Alagoas, Bahia, Paraíba, Distrito Federal, Goiás, Mato Grosso do Sul, Espírito Santo, Minas Gerais, Rio de Janeiro, São Paulo, Paraná, Santa Catarina e Rio Grande do Sul, em áreas de Caatinga, Cerrado, Mata Atlântica e Pampa (Ferreira \& Martins 2005; BFG 2015). Nove espécies são endêmicas do Brasil e nenhuma do Paraná. (BFG 2015).

O estado do Paraná possui uma rica biodiversidade, proveniente da ação conjunta de diferentes fatores como clima, relevo e hidrografia (Labiak 2014). Um levantamento da flora estadual estima a existência de pelo menos 6.524 espécies de plantas vasculares nativas (Kaehler et al. 2014). Até o momento, não há tratamento taxonômico ou florístico feito para Buddleja no estado, apesar da existência de fontes de informação taxonômica para Santa Catarina (Smith et al. 1976), São Paulo (Ferreira \& Martins 2005) e Paraguai (Soria 2011), além da Flora Brasiliensis (Schmidt 1862) e de duas revisões não publicadas, disponíveis apenas em teses para o gênero no Brasil (Ferreira 1988; Coelho 2017). O gênero foi monografado para a região neotropical (Norman 2000).

O presente trabalho teve como objetivo geral o tratamento taxonômico das espécies nativas e cultivadas de Buddleja ocorrentes no estado do Paraná. Este tratamento conta com chaves de identificação para as espécies e subespécies, descrições, dados sobre floração, frutificação e de distribuição e ilustrações.

\section{Material e Métodos}

Área de estudo

O estado do Paraná está localizado na Região Sul do Brasil e possui área de aproximadamente $201.203 \mathrm{~km}^{2}$. A maior parte do seu território situa- se na zona de clima subtropical, tendo apenas a parte ao norte do trópico de Capricórnio situada na zona tropical (Maack 2012).

Segundo Labiak (2014), a vegetação do Paraná possui tipologias vegetais predominantemente florestais, além de áreas de campos (Estepes) e Cerrados (Savanas) que são restritas a algumas regiões do estado. Na zona litorânea encontramse espécies adaptadas a condições de salinidade e hipóxia dos manguezais e também de formações pioneiras com elementos majoritariamente herbáceos, ocupando as regiões em que o solo é mais bem drenado. Avançando para o continente, a vegetação apresenta formas arbustiva e arbórea, formando o cenário chamado de Restinga. Na região da Serra do Mar ocorre a Floresta Ombrófila Densa, também conhecida como Mata Atlântica stricto sensu, sendo este o mais diverso e complexo tipo de vegetação do estado, com abundância de espécies em todos os seus estratos florestais. No Primeiro Planalto encontram-se áreas de campos e uma mescla dos elementos de Mata Atlântica com os de Floresta com Araucária (Floresta Ombrófila Mista). O Segundo Planalto abrange as maiores áreas de campo (Estepes) do estado, sendo que estes ocorrem entremeados com capões de Floresta com Araucária. Neste Planalto são encontradas áreas relictuais de Cerrado. Já no Terceiro Planalto ocorre a Floresta Estacional Semidecidual. Próximo aos limites leste deste Planalto ainda há o predomínio de Campos e de Florestas com Araucária. Na região central a Floresta com Araucária é dominante, os campos tornam-se mais raros e surgem os primeiros elementos da Floresta Estacional Semidecidual, que tende a dominar as paisagens no sentido oeste (Labiak 2014). Infelizmente, a cobertura vegetal do estado sofreu grandes alterações ao longo do tempo, sendo substituída por áreas urbanas ou de uso agropecuário. Desse modo, o Paraná sofreu um forte desmatamento e atualmente conta com poucas unidades de conservação onde ainda resta parte de sua vegetação natural (IPARDES 2016).

\section{Análise do material botânico}

O material analisado para este trabalho provém de coletas realizadas pelos autores ao longo de 2016, processadas segundo Fidalgo \& Bononi (1989), e incluídas no herbário UPCB, além de exsicatas selecionadas depositadas nos herbários MBM e UPCB (acrônimos segundo Thiers, continuamente atualizado). Material adicional foi utilizado apenas para espécies que não possuem coletas com frutos ou que possuem apenas uma 
coleta para o Paraná. Também foram realizadas consultas a imagens em bases de dados na internet, entre elas o Herbário Virtual Reflora (2016), rede Species Link (CRIA 2016) e Jstor Plants (2016). A partir do material botânico selecionado, foram feitas análises morfológicas das estruturas vegetativas e reprodutivas com auxílio de microscópio estereoscópico. As medidas das estruturas foram feitas com paquímetro digital. Informações sobre os períodos de floração, de frutificação e características do material fresco foram obtidas a partir das etiquetas das exsicatas. A terminologia morfológica segue Gonçalves \& Lorenzi (2007) e a descrição do gênero foi baseada em Norman (2000) e Ferreira \& Martins (2005). A descrição das estípulas segue Norman (2000), e inclui estípulas reduzidas a uma linha interpeciolar, ou seja, uma pequena protuberância encontrada entre a base dos pecíolos. A medida da corola foi efetuada incluindo-se o tubo e lobos da corola. As flores são consideradas subsésseis quando o pedicelo é ausente ou tem medida inferior a $1 \mathrm{~mm}$. Por falta de informação nas etiquetas das exsicatas, não há dados sobre a altura das plantas para todas as espécies e, nestes casos, esta informação foi omitida.

Os mapas de distribuição foram confeccionados no programa QGIS 2.14.2, com coordenadas obtidas em campo e de exsicatas, ou estimadas com base em informações das localidades. Quando necessário essas informações foram convertidas através de ferramenta disponibilizada pelo CRIA (2016). Nos casos da ausência de coordenadas no material botânico, estas foram estimadas através do Google ${ }^{\odot}$ Maps (2016).

Ilustrações adicionais para todas as espécies tratadas aqui podem ser encontradas em Norman (2000).

\section{Resultados e Discussão}

O estado do Paraná possui dez espécies e duas subespécies de Buddleja, sendo B. ramboi um novo registro para o estado, $B$. davidii cultivada, $B$. elegans abrangendo duas subespécies, e seis táxons endêmicos do Brasil (B. brachiata, B. cuneata, $B$. elegans subsp. elegans, $B$. hatschbachii, $B$. oblonga e B. ramboi). A maior diversidade de espécies está associada à porção leste do estado, predominantemente em áreas de Campos e Floresta com Araucária. Os táxons com maior número de registros de ocorrência no estado são $B$. elegans subsp. elegans e $B$. stachyoides.

\section{Tratamento taxonômico}

Buddleja L., Sp. Pl. 1: 11. 1753.

Subarbustos, arbustos eretos ou escandentes, raro arvoretas, funcionalmente dióicos ou polígamo-dióicos. Caules cilíndricos a quadrangulares; glabrescentes a velutinos. Folhas opostas, sésseis, raro pecioladas, opostas-cruzadas; estípula interpeciolar auriculada, membranácea ou reduzida a uma linha. Inflorescência em tirso apical, subapical ou raramente axilar, variadamente ramificado, com glomérulos ou cimeiras sésseis ou com pedúnculo de até $3,5 \mathrm{~cm}$ compr. Flores actinomorfas, 4-meras, sésseis ou pediceladas, morfologicamente hermafroditas; cálice membranáceo, cartáceo ou coriáceo, campanulado ou tubuloso, esverdeado; corola tubulosa, raro campanulada ou hipocrateriforme, amarela, branca, creme, creme-esverdeada ou lilás; estames 4 , adnatos às pétalas; ovário súpero, ovóide, castanho, placentação axilar; estigma capitado. Fruto cápsula septicida, elíptica, castanha. Sementes numerosas, fusiformes, reniformes ou piriformes.

\section{Chave de identificação das espécies de Buddleja ocorrentes no Paraná}

1. Arbusto escandente; estípula auriculada; corola campanulada............................ 1. Buddleja brachiata

1'. Subarbustos, arbustos eretos ou arvoretas; estípula reduzida a uma linha ou membranácea; corola tubulosa ou hipocrateriforme

2. Corola hipocrateriforme, lilás ....................................................................... Buddleja davidii

2'. Corola tubulosa, amarela, branca, creme ou creme-esverdeada .............................................. 3

3. Inflorescência axilar ou subapical; glomérulos pedunculados na base e sésseis no ápice dos ramos das inflorescências. 7. Buddleja oblonga

3'. Inflorescência apical; cimeiras ou glomérulos exclusivamente sésseis ou exclusivamente pedunculados

4. Glomérulos sésseis ou subsésseis. 9. Buddleja stachyoides

4'. Glomérulos ou cimeiras pedunculados 5 
5. Inflorescência com ramos secundários ausentes; corola 10,2-20,5 mm compr.

6. Buddleja hatschbachii

5'. Inflorescência com ramos secundários presentes; corola 2,6-12,3 mm compr.

6. Cimeiras ou glomérulos com cerca de 4 flores; corola 11,7-12,3 mm compr.

5. Buddleja grandiflora

6'. Cimeiras ou glomérulos com 6-18 flores; corola 2,6-7,3 mm compr.

7. Cálice campanulado; lobos da corola com face abaxial glabra.

10. Buddleja thyrsoides subsp. angusticarpa

7'. Cálice tubuloso; lobos da corola com face abaxial velutina 8

8. Folhas com face adaxial velutina, margem crenado-sinuosa .......... 8. Buddleja ramboi

8'. Folhas com face adaxial glabrescente ou pubescente, margem inteira a crenada, denteada ou serreada

9. Lâmina 1,4-2,8 cm larg., elíptica, base truncada ou cuneada

2. Buddleja cuneata

9'. Lâmina 0,5-1,4 cm larg., estreito-elíptica ou estreito-oblanceolada a oblanceolada, base decorrente a aguda.

4. Buddleja elegans

1. Buddleja brachiata Cham. \& Schltdl., Linnaea 2: 599.1827. Figs. 1a; 2a

Arbustos escandentes, dióicos. Caules quadrangulares, velutinos nos ramos jovens, glabrescentes nos ramos mais velhos. Folhas sésseis; estípula auriculada, $0,1 \times 0,4 \mathrm{~mm}$; lâmina $5,5-11,8 \times 1,6-4,4 \mathrm{~cm}$, oval a elíptica, cartácea, face adaxial glabrescente, face abaxial pubescente, margem inteira, base decorrente, ápice agudo a atenuado. Tirso apical de glomérulos sésseis a subsésseis; ramos secundários presentes, perpendiculares em relação ao ramo primário; bractéolas 1,8-2 mm compr. Flores subsésseis, ca. 5 por glomérulo; cálice 2,2-2,6 × 2,6-3 mm, membranáceo, tubuloso, velutino, lobos $0,8-1,1$ $\times 1,5-1,8 \mathrm{~mm}$, agudos, face abaxial velutina com tricomas estrelados, face adaxial glabra; corola 2,7-3,3 $\times 2,5-3 \mathrm{~mm}$, campanulada, creme, tubo externamente glabrescente, internamente piloso, lobos 1,5-1,8 × 1,6-1,8 mm, arredondados, face abaxial pubescente, com tricomas estrelados, face adaxial glabra; estames no terço superior do tubo da corola, ca. $1 \mathrm{~mm}$ compr.; ovário $1-1,3 \times 0,7-1$ $\mathrm{mm}$, pubescente; estilete $0,7-0,9 \mathrm{~mm}$ compr. Frutos não observados.

Material selecionado: Londrina, 22.VI.2016, fl., J.S. Carneiro 252 (MBM).

Material adicional: BRASIL. SÃO PAULO: Piracicaba, 19.VIII.1894, fl., A. Puttemans 10485 (NY, imagem digital).

Espécie endêmica do Brasil, ocorrendo em Goiás, Minas Gerais, Rio de Janeiro, São Paulo e Paraná (BFG 2015). No Paraná ocorre em Floresta Estacional Semidecidual. Coletada com flores em junho.
Reconhecida pelo hábito escandente, estípula auriculada, ramos da inflorescência dispostos perpendicularmente entre si e com pequenos pares de glomérulos geralmente sésseis.

2. Buddleja cuneata Cham., Linnaea 8: 17. 1833.

Figs. 1b; 2a

Arbustos eretos, dióicos, $1 \mathrm{~m}$ alt. Caules cilíndricos a subquadrangulares, às vezes alados nos ramos mais jovens, velutinos. Folhas sésseis; estípula reduzida a uma linha; lâmina 2-7 × 1,4-2,8 $\mathrm{cm}$, elíptica, coriácea, face adaxial glabrescente ou pubescente, face abaxial velutina, margem crenada a denteada, base truncada ou cuneada, ápice arredondado a agudo. Tirso apical de cimeiras ou glomérulos pedunculados; ramos secundários presentes, eretos; bractéolas 2-4 $\mathrm{mm}$ compr.; pedúnculo 4-15 mm compr. Flores sésseis ou pediceladas, $6-10$ por glomérulo; pedicelo $0,6-1,8$ mm compr., velutino; cálice 3,6-5,8 × 2,3-3,6 mm, membranáceo, tubuloso, pubescente a velutino, lobos 1,2-2 × 1,1-1,8 mm, agudos, face abaxial e adaxial velutinas com tricomas estrelados; corola 4,8-5,7 × 1,7-2,3 mm, tubulosa, branca ou creme, tubo externamente velutino e internamente piloso, lobos 1,1-1,8 × 1,2-2,4 mm, arredondados, face abaxial velutina com tricomas estrelados, face adaxial glabra; estames no terço superior do tubo da corola, 0,6-1,2 mm compr.; ovário 1,7-2,2 × 1,3-2 $\mathrm{mm}$, pubescente a velutino; estilete $2-2,52$ $\mathrm{mm}$ compr. Frutos 7-9 $\times 3-4 \mathrm{~mm}$. Sementes 1,7-2 $\mathrm{mm}$ compr., fusiformes.

Material selecionado: Palmeira, 26.X.1982, fl., G. Hatschbach 45734 (MBM). Ponta Grossa, 11.X.1967, fl., G. Hatschbach 17431 (MBM). 


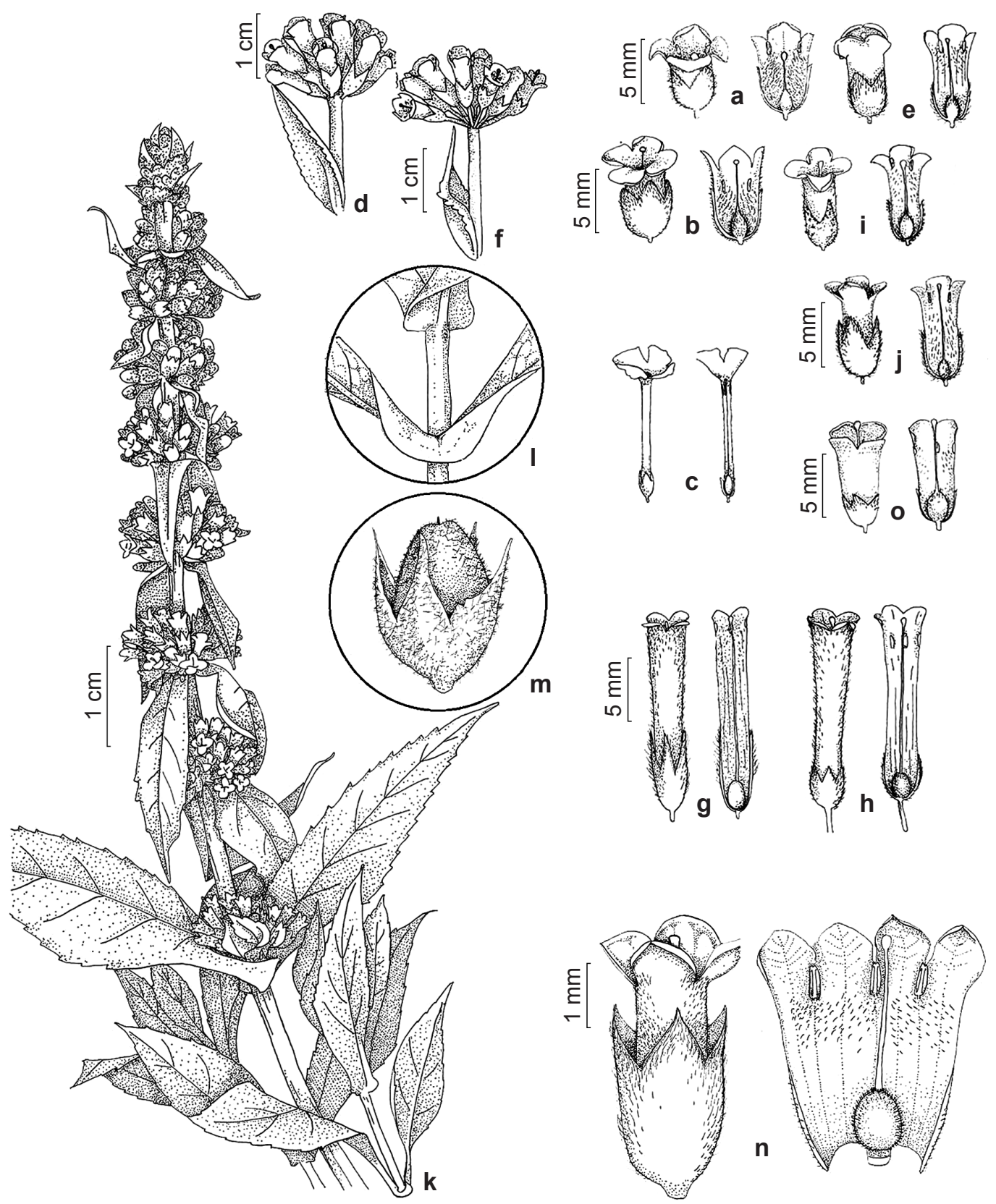

Figura 1 - a. Buddleja brachiata - flor inteira e seccionada. b. B. cuneata - flor inteira e seccionada. c. B. davidii-flor inteira e seccionada. d. B. elegans subsp. elegans - cimeira. e. B. elegans subsp. elegans - flor inteira e seccionada. f. B. elegans subsp. angustata - cimeira. g. B. grandiflora - flor inteira e seccionada. h. B. hatschbachii - flor inteira e seccionada. i. B. oblonga - flor fechada e aberta. j. B. ramboi - flor inteira e seccionada. k-n. B. stachyoides - k. ramo fértil; 1 . base da folha; $\mathrm{m}$. fruto; $\mathrm{n}$. flor inteira e seccionada. o. B. thyrsoides subsp. angusticarpa - flor inteira e seccionada. (a. Carneiro 252; b. Hatschbach 17431; c. Cordeiro 1834; d,e. Hatschbach 24835; f. Hatschbach 19779; g. Ribas 1226; h. Hatschbach 78225; i. Hatschabch 30742; j. Hatschbach 53674; k-n. Lannoy 04; o. Hatschbach 30793). Figure 1 - a. Buddleja brachiata - whole and sectioned flower. b. B. cuneata - whole and sectioned flower. c. B. davidii-whole and sectioned flower. d. B. elegans subsp. elegans - cyme. e. B. elegans subsp. elegans - whole and sectioned flower. f. B. elegans subsp. angustata-cyme. g. B. grandiflora - whole and sectioned flower. h. B. hatschbachii - whole and sectioned flower. i. B. oblonga-whole and sectioned flower. j. B. ramboi - whole and sectioned flower. k-n. B. stachyoides - k. fertile branch; 1 leaf base; $\mathrm{m}$. fruit; $\mathrm{n}$. whole and sectioned flower. o. B. thyrsoides subsp. angusticarpa - whole and sectioned flower. (a. Carneiro 252; b. Hatschbach 17431; c. Cordeiro 1834; d,e. Hatschbach 24835; f. Hatschbach 19779; g. Ribas 1226; h. Hatschbach 78225; i. Hatschabch 30742; j. Hatschbach 53674; k-n. Lannoy 04; o. Hatschbach 30793). 
Material adicional: BRASIL. RIO GRANDE DO SUL: São Francisco de Paula, 9.I.1955, fr., B. Rambo (HUCS 6726).

Espécie endêmica do Brasil, encontrada no Paraná, Santa Catarina e Rio Grande do Sul (BFG 2015). No Paraná ocorre em região de Campos entremeados por capões de Floresta com Araucária. Coletada com flores em outubro.
Espécie de ocorrência rara, reconhecida pelas folhas de base cuneada e inflorescência com vários ramos secundários eretos.

3. Buddleja davidii Franch., Nouv. Arch. Mus. Hist. Nat., sér. 2 10: 65. 1887.

Figs. 1c; $2 \mathrm{a}$

Arbustos eretos, ca. $1 \mathrm{~m}$ alt. Caules cilíndricos a subquadrangulares, velutinos nos ramos jovens e
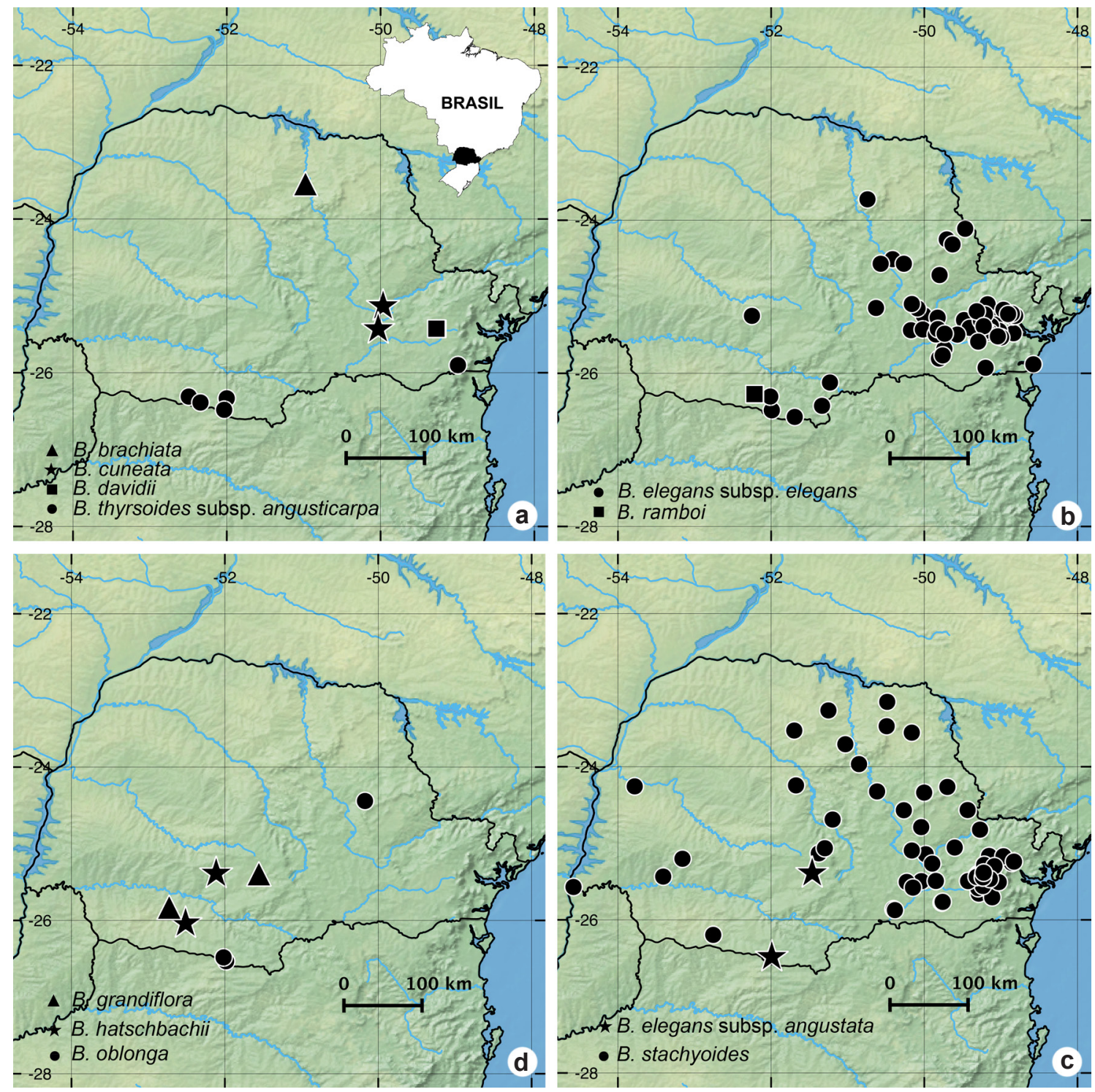

Figura 2 - a-d. Mapas de distribuição das espécies de Buddleja no estado do Paraná - a. Buddleja brachiata, B. cuneata, B. davidii, B. thyrsoides subsp. angusticarpa; b. Buddleja elegans subsp. elegans, B. ramboi; c. Buddleja elegans subsp. angustata, B. stachyoides; d. B. grandiflora, B. hatschbachii, B. oblonga.

Figure 2 - a-d. Distribution maps for Buddleja species in the state of Paraná-a. Buddleja brachiata, B. cuneata, B. davidii, B. thyrsoides subsp. angusticarpa; b. Buddleja elegans subsp. elegans, B. ramboi; c. Buddleja elegans subsp. angustata, B. stachyoides; d. Buddleja. grandiflora, B. hatschbachii, B. oblonga. 
pilosos nos ramos mais velhos. Folhas pecioladas; pecíolo 1-5 mm compr.; estípula reduzida a uma linha ou membranácea; lâmina $2,5-8,5 \times 0,5-1,7$ $\mathrm{cm}$, estreito-elíptica elíptica, cartácea, face adaxial glabrescente, face abaxial velutina, margem repanda a pouco denteada, base atenuada, ápice agudo. Tirso apical de cimeiras pedunculadas; ramos secundários presentes, eretos; bractéolas 1,2-1,5 mm compr.; pedúnculo $2-5 \mathrm{~mm}$ compr.; Flores pediceladas, ca. 8 por cimeira; pedicelo 1,2-1,4 mm compr., pubescente; cálice 2,4-2,7 $\times 1-1,4 \mathrm{~mm}$, membranáceo, tubuloso, piloso, lobos $0,6-0,9 \times 0,3-0,9 \mathrm{~mm}$, agudos, face abaxial esparsa com tricomas estrelados, face adaxial glabra; corola 10,4-11,8 × 1,1-1,5 $\mathrm{mm}$, hipocrateriforme, lilás, tubo externamente pubescente e internamente piloso, lobos 1,2-1,3 $\times 1,7-2 \mathrm{~mm}$, arredondados, face abaxial e adaxial glabras; estames na metade do tubo da corola, ca. $1 \mathrm{~mm}$ compr.; ovário 1,6 $\times 0,7 \mathrm{~mm}$, glabrescente; estilete 1,2 mm compr. Frutos não observados. Material selecionado: Curitiba, 7.II.1992, fl., $J$. Cordeiro 1834 (MBM); 23.XII.1977, fl., N. Imaguire 5331 (MBM); 16.XII.1974, fl., R. Kummrow 780 (MBM).

Espécie exótica no Brasil, nativa da região central da China, Tibet e Japão. É frequentemente cultivada em regiões temperadas e subtropicais (Norman 2000). No Paraná é encontrada em cultivo, como ornamental, na região de Curitiba. Coletada com flores em fevereiro.

Pode ser reconhecida pela inflorescência vistosa com flores lilases e folhas com poucos tricomas na superfície adaxial.

4. Buddleja elegans Cham. \& Schltdl., Linnaea 2: 594.1827.

Figs. 1d-f; 2b,c

Arbustos ou subarbustos eretos ou arvoretas, polígamo-dióicos, 1-2 m alt. Caules cilíndricos, velutinos a glabrescentes. Folhas sésseis; estípula reduzida a uma linha; lâmina 1,6-7,7 × 0,5-1,4 $\mathrm{cm}$, estreito-elíptica ou estreito-oblanceolada a oblanceolada, coriácea, face adaxial glabrescente a pubescente, face abaxial velutina, margem inteira a serreada, base decorrente a aguda, ápice atenuado a agudo. Tirso apical de cimeiras ou glomérulos pedunculados; ramos secundários presentes, eretos; bractéolas 1,3-5,4 mm compr.; pedúnculo 3-26,5 $\mathrm{mm}$ compr. Flores sésseis, subsésseis ou pediceladas, 6-17 por cimeira; pedicelo 1-3,2 mm compr., velutino; cálice 2,9-4,6 × 1,6-2,5 mm, membranáceo, tubuloso, velutino, lobos $0,6-1,6 \times 0,6-1,8 \mathrm{~mm}$, agudos; corola 5-6 × 1,5-2,3 mm, tubulosa, branca ou creme, tubo externamente velutino e internamente piloso, lobos $0,8-1,8 \times 1,2-2 \mathrm{~mm}$, arredondados; estames no terço superior do tubo da corola, 0,5-1 mm compr.; ovário 0,9-3,5 × 1,5-2 mm, pubescente a velutino; estilete 2,5-3,2 $\mathrm{mm}$ compr. Frutos (vistos apenas em B. elegans subsp. elegans) 3,8-6 × 2,5-2,8 mm. Sementes 1,4-1,8 mm compr., piriformes.

Esta espécie também é encontrada no Uruguai, Argentina, Paraguai (Norman 2000). No Brasil ocorre no Mato Grosso do Sul, Minas Gerais, São Paulo, Paraná, Santa Catarina e Rio Grande do Sul (BFG 2015).

Possui grande variação no tamanho da lâmina, que pode estar relacionada com variação clinal (Norman 2000). Caracteriza-se por suas folhas coriáceas, estreito-elípticas ou estreitooblanceoladas a oblanceoladas, densamente velutinas na superfície abaxial e glomérulos com flores brancas ou creme. É frequentemente encontrada, na bibliografia e em herbários identificada como Buddleja campestris (Vell.) Walp., que é um sinônimo heterotípico (BFG 2015).

\section{Chave de identificação das subespécies de Buddleja elegans do Paraná}

1. Flores sésseis ou subsésseis; lobos do cálice com face abaxial velutina e adaxial glabra.....

4a. Buddleja elegans subsp. elegans

1'. Flores com pedicelo 1-3,2 mm compr.; lobos do cálice com face abaxial glabra e adaxial velutina..... 4b. Buddleja elegans subsp. angustata

4a. Buddleja elegans Cham. \& Schltdl. subsp. elegans, Linnaea 2: 594. $1827 . \quad$ Figs. 1d,e; 2b Arbustos ou subarbustos eretos ou arvoretas, 1,5-2 m alt. Caules cilíndricos, velutinos nos ramos jovens e glabrescentes nos ramos mais velhos.
Folhas com lâmina 1,6-7,7 ×0,5-1,4 cm, estreito elíptica ou estreito-oblanceolada a oblanceolada, face adaxial glabrescente a pubescente, margem inteira na base e crenada a serreada no ápice, base decorrente a aguda, ápice agudo. Tirso de 
glomérulos pedunculados; bractéolas 1,3-5,4 mm compr.; pedúnculo 3-26,3 mm compr.;. Flores sésseis ou subsésseis, 6-17 por cimeira; cálice $2,9-4,6 \times 1,6-2,5 \mathrm{~mm}$, lobos $0,6-1,2 \times 0,6-1,2$ $\mathrm{mm}$, face abaxial velutina com tricomas estrelados, às vezes glandulares, face adaxial glabra; corola $5-5,7 \times 1,5-2,3 \mathrm{~mm}$, branca ou creme, lobos $0,8-1,8$ $\times 1,2-2 \mathrm{~mm}$, face abaxial velutina a pubescente, com tricomas estrelados e glandulares, face adaxial glabra; estames 0,5-1 mm compr.; ovário 0,9-2,1 × 1,7-1,7 mm, pubescente a velutino; estilete 2,5-3,2 $\mathrm{mm}$ compr. Frutos 3,8-6 × 2,5-2,8 mm. Sementes 1,4-1,8 mm compr., piriformes.

Material selecionado: Guaratuba, 18.IX.1997, fl., E.P. Santos 339 (UPCB). Piraquara, 12.VIII.2015, fl., L.C. Lannoy 01 (UPCB). Ponta Grossa, 20.IX.2009, fl., R.R. Völtz 54 (UPCB). São Jerônimo da Serra, 27.X.1970, fl., G. Hatschbach 24835 (UPCB).

Material adicional: BRASIL. SÃO PAULO: Campos do Jordão, 15.XII.1966, fr., J. Mattos 14346 (SP). Itararé, 20.X.1966, fr., J. Mattos 14037 (SP).

Esta subespécie é endêmica do Brasil, ocorrendo no Mato Grosso do Sul, Minas Gerais, São Paulo, Paraná, Santa Catarina e Rio Grande do Sul (BFG 2015). No Paraná, ocorre em áreas de Floresta Estacional Semidecidual, Floresta Ombrófila Densa e Campos entremeados por capões de Floresta com Araucária. Coletada com flores de agosto a outubro.

Distingue-se-se de Buddleja elegans subsp. angustata por possuir flores sésseis e pelos lobos do cálice com face abaxial velutina (versus glabra) e adaxial glabra (versus velutina).

4b. Buddleja elegans Cham. \& Schltdl. subsp. angustata (Benth.) E.M.Norman, Kurtziana 24: 192. 1995.

Figs. 1f; 2c

Arbustos eretos, $1 \mathrm{~m}$ alt. Caules cilíndricos, velutinos. Folhas com lâmina 3,3-5,5 × 0,5-1 cm, estreito-elíptica, face adaxial pubescente, margem inteira a crenada, base aguda, ápice atenuado. Tirso de cimeiras pedunculadas; bractéolas 2,3-3,6 mm compr.; pedúnculo 3,6-17,9 mm compr. Flores pediceladas, 7-13 por cimeira; pedicelo 1-3,2 mm compr., velutino; cálice 3,6-4,4×1,9-2,5 mm, lobos 1,3-1,6 × 1,2-1,8 mm, face abaxial glabra, face adaxial velutina, com tricomas estrelados; corola 5-6 × 1,6-2,1 mm, branca, lobos 1,3-1,5 × 1,5-1,7 $\mathrm{mm}$, face abaxial velutina, com tricomas estrelados e glandulares, face adaxial glabra; estames 0,7-1 mm compr.; ovário 1,9-3,5 × 1,5-2 mm, velutino; estilete 2,5-2,6 mm compr. Frutos não observados. Material selecionado: Mangueirinha, 21.IX.1968, fl., $G$. Hatschbach 19779 (UPCB).
Ocorre no Uruguai, Argentina e Paraguai. (Norman 2000). No Brasil também é encontrada no Rio Grande do Sul (BFG 2015). No Paraná cresce em áreas de Floresta com Araucária entremeada por Campos. Coletada com flores em setembro.

Distingue-se de Buddleja elegans subsp. elegans, principalmente, por possuir pedicelos com no mínimo $1 \mathrm{~mm}$ de comprimento e pelo indumento dos lobos do cálice.

5. Buddleja grandiflora Cham. \& Schltdl., Linnaea 2: 596.1827.

Figs. 1g; 2d

Arbustos eretos, monóicos, 1,5 m alt. Caules cilíndricos a subquadrangulares, velutinos. Folhas sésseis; estípula reduzida a uma linha; lâmina 4,5-11,5 $\times 0,7-1,8 \mathrm{~cm}$, estreito-elíptica, cartácea, face adaxial pubescente, face abaxial velutina, margem crenada, base atenuada auriculada em torno do pecíolo, ápice agudo. Tirso apical de cimeiras ou glomérulos pedunculados; ramos secundários presentes, eretos; bractéolas 3,7-4,1 mm compr.; pedúnculo 1,1-6,2 mm compr. Flores pediceladas, ca. 4 por cimeira; pedicelo 0,7-2,1 mm compr., pubescente; cálice 4,8-5,7 × 2,2-2,8 mm, membranáceo, tubuloso, pubescente, lobos 1,7-2,1 × 1,1-1,3 mm, agudos, face abaxial velutina, com tricomas estrelados, face adaxial glabra; corola 11,7-12,3 × 1,6-1,8 mm, tubulosa, amarela, tubo externamente velutino e internamente piloso, lobos 1,8-1,9 × 1,2-1,3 mm, arredondados, face abaxial velutina, com tricomas estrelados, face adaxial glabra; estames no terço superior do tubo da corola, 0,8-1,2 mm compr.; ovário 2-3,1 × 1-1,5 mm, velutino; estilete 7,6-8,7 mm compr. Frutos 4,8-7,4 × 3,2-4 mm. Sementes $0,5-0,7 \mathrm{~mm}$ compr., reniformes.

Material selecionado: São João, 21.III.1910, fl. e fr., P.K.H. Dusén 9354 (NY).

Material adicional: BRASIL. SANTA CATARINA: Curitibanos, 11.III.1996, fl. e fr., O.S. Ribas 1226(MBM).

Encontrada na Argentina e Uruguai (Norman 2000). No Brasil, ocorre em São Paulo, Paraná, Santa Catarina e no Rio Grande do Sul (BFG 2015). No Paraná, é encontrada em áreas de transição entre a Floresta com Araucária e a Floresta Estacional Semidecidual. Coletada com flores e frutos em março.

Buddleja grandiflora assemelha-se a $B$. hatschbachii, da qual difere pelas flores um pouco menores, (corola 11,7-12,3 × 1,6-1,8 mm versus $10,2-20,5 \times 1,9-3,5 \mathrm{~mm})$, corola amarela (versus creme-esverdeada) e por apresentar ramos secundários na inflorescência (versus ramos secundários ausentes). 
6. Buddleja hatschbachii E.M.Norman \& L.B.Sm., Fl. Ilustr. Catarin., Loganiáceas: 15. 1976.

Figs. 1h; 2d

Arbustos eretos, monóicos, 0,7-1 $\mathrm{m}$ alt. Caules cilíndricos a quadrangulares, pubescentes a velutinos às vezes glabrescentes nos ramos mais velhos. Folhas sésseis; estípula reduzida a uma linha; lâmina 6-21 × 1,6-7 cm, elíptica a oval, cartácea, face adaxial pubescente nas folhas velhas e velutina nas folhas jovens, face abaxial velutina, margem crenada a denteada ou serreada, base atenuada auriculada em torno do pecíolo, ápice agudo. Tirso apical de cimeiras ou glomérulos pedunculados; ramos secundários ausentes; bractéolas 2,5-4,8 mm compr.; pedúnculo 7,8-34,8 mm compr. Flores sésseis a pediceladas, 5-9 por cimeira; pedicelo até 1,2 $\mathrm{mm}$ compr., pubescente a velutino; cálice 4,7-7,3 × 3-4 mm, membranáceo, tubuloso, pubescente a velutino, lobos 1,4-2,6 × 1,9-3,5 mm, agudos, face abaxial velutina, com tricomas estrelados, face adaxial glabra; corola 10,2-20,5 × 1,9-3,5 mm, tubulosa, creme-esverdeada, tubo externamente pubescente e internamente glabro, lobos 1-2 × 1,1-2,4 mm, arredondados, face abaxial velutina, com tricomas estrelados, face adaxial glabra; estames no quinto superior do tubo da corola, 1,3-1,8 mm compr.; ovário $2-5 \times 1,5-2,8 \mathrm{~mm}$, pubescente a velutino; estilete 6,6-15,8 mm compr. Frutos 7-8,5 × 4,8-6 $\mathrm{mm}$. Sementes 0,6-0,3 mm compr., piriformes.

Material selecionado: Guarapuava, 18.VIII.2009, fl., E.M. Silva 7300 (MBM). Mangueirinha, 20.X.1966, fl., G. Hatschbach 15173 (UPCB, isótipo).

Material adicional: BRASIL. RIO GRANDE DO SUL: Gramado, X.1997, fl., M. Sobral 8607. SANTA CATARINA: Petrolândia, 14.XII.2015, fr., G.P. Coelho 70 (ICN). Urubici, 18.X.2004, fl., G. Hatschbach 78225 (MBM).

Espécie endêmica do Brasil. Ocorre no Paraná, Santa Catarina e Rio Grande do Sul (BFG 2015). No Paraná pode ser encontrada em região de Floresta com Araucária e Campos. Coletada com flores de agosto a outubro.

Esta é uma espécie de ocorrência muito rara, somente encontrada na porção leste do planalto sul brasileiro a aproximadamente $1.000 \mathrm{~m}$ de elevação (Norman 2000).

7. Buddleja oblonga Benth., Prodr. 10: 442. 1846.

Figs. 1i; 2d

Arbustos eretos, dióicos, 1,2-1,5 m alt. Caules cilíndricos a quadrangulares, pubescentes a velutinos nos ramos mais jovens e pubescentes a glabrescentes nos ramos mais velhos. Folhas sésseis; estípula reduzida à uma linha a levemente membranácea; lâmina 3,2-16,8 × 0,5-3,1 cm, estreito-elíptica, membranácea à cartácea, face adaxial glabrescente, face abaxial pubescente ou pilosa próximo as nervuras, margem crenada à denteada, base atenuada, ápice agudo. Tirso axilar ou subapical de glomérulos; ramos secundários ausentes; bractéolas 1,2-3,6 mm compr.; glomérulos superiores sésseis e inferiores com pedúnculo até $7 \mathrm{~mm}$ compr.; Flores sésseis a subsésseis, 6-9 por glomérulo; cálice 3,6-5,4 × 1,9-2,8 mm, membranáceo, tubuloso, pubescente a velutino, lobos 1,4-2 × 0,8-1,4 mm, agudos, face abaxial pubescente, com tricomas estrelados, face adaxial glabra; corola 5,4-7,5 $\times$ 1,4-2,3 mm, tubulosa, branca, tubo externamente pubescente e internamente piloso, lobos 1,3-1,8 $\times$ 1,5-2,5 mm, agudos, face abaxial e adaxial glabras; estames no terço superior do tubo da corola, 0,6-1,1 mm compr.; ovário 1,2-3 × 1-2,2 mm, pubescente a piloso; estilete 2,6-4,1 mm compr. Frutos não observados.

Material selecionado: Palmas, 29.X.1956, fl., G. Hatschbach 3430 (MBM); 20.XI.1972, fl., G. Hatschbach 30742 (MBM). Piraí do Sul, 18.IX.1975, fl., G. Hatschbach 37055 (MBM).

Espécie endêmica do Brasil encontrada nos estados de Minas Gerais, Rio de Janeiro, São Paulo e Paraná (BFG 2015), onde ocorre em região de Campos. Coletada com flores de setembro a novembro.

Embora a forma e consistência das folhas possam ocasionalmente lembrar às de Buddleja brachiata, esta espécie difere daquela devido ao hábito arbustivo, estípula reduzida a uma linha (versus estípulas auriculadas) e por não possuir ramos secundários na inflorescência (versus ramos secundários presentes e eretos).

8. Buddleja ramboi L.B.Sm., Sellowia 6: 301. 1954.

Figs. 1j; $2 \mathrm{~b}$

Arbustos eretos, dióicos, 1,5 m alt. Caules cilíndricos, velutinos. Folhas sésseis; estípula reduzida a uma linha; lâmina 1,5-4,2 ×0,3-0,8 cm, oblanceolada ou obovada, coriácea, face adaxial velutina, face abaxial velutina, margem crenadosinuosa, base aguda, ápice atenuado. Tirso apical de cimeiras pedunculadas; ramos secundários presentes, paralelos ao ramo primário; bractéolas 2,1-5,1 mm compr.; pedúnculo 1,9-11,4 mm compr. Flores pediceladas, ca. 11 por cimeira; pedicelo 1,4-3,2 mm compr., velutino; cálice 4,1-5,8 × 2,4-3 mm, coriáceo, tubuloso, velutino, lobos 
$1-6,6 \times 1,2-2,1 \mathrm{~mm}$, agudos, face abaxial velutina, com tricomas estrelados e glandulares, face adaxial velutina com tricomas estrelados; corola 5,1-7,3 $\times$ 1,3-1,8 mm, tubulosa, branca, tubo externamente velutino e internamente piloso, lobos $1,1-2,3 \times$ 1,6-3 mm, arredondados, face abaxial velutina, com tricomas estrelados e glandulares, face adaxial glabra; estames no terço superior do tubo da corola, 0,7-0,9 mm compr.; ovário $0,9-1,8 \times 0,7-1,5 \mathrm{~mm}$, pubescente a velutino; estilete $2,3-2,7 \mathrm{~mm}$ compr. Frutos 5,5-7,5 × 2,5-3 mm. Sementes 2,5-4 mm compr., fusiformes.

Material selecionado: Palmas, 6.XII.1989, fl., G. Hatschbach 53674 (UPCB).

Material adicional: BRASIL. RIO GRANDE DO SUL: Jaquirana, 18.III.2016, fr., G.P. Coelho 100 (ICN).

Espécie endêmica do Brasil. Ocorre no Paraná, Santa Catarina e Rio Grande do Sul (BFG 2015). No Paraná pode ser encontrada em região de Campos. Coletada com flores em dezembro.

Esta é uma espécie de ocorrência muito rara, até o momento encontrada somente no município de Palmas, Paraná. Pode ser facilmente confundida com Buddleja elegans subsp. angustata, da qual se distingue pelas folhas menores (lâmina 3,3-5,5 $\times$ $0,5-1 \mathrm{~cm}$ versus $1,5-4,2 \times 0,3-0,8 \mathrm{~cm})$, com margem crenado-sinuosa e face adaxial velutina (versus margem inteira a crenada e face adaxial pubescente).

\section{Buddleja stachyoides Cham. \& Schltdl., Linnaea}

\section{2: 597.1827.}

Figs. 1k-n; 2c

Arbustos ou subarbustos eretos, monóicos, $1,6-2 \mathrm{~m}$ alt. Caules quadrangulares às vezes cilíndricos nos ramos mais velhos, pubescentes a velutinos variando entre ramos jovens e velhos. Folhas sésseis; estípula reduzida a uma linha; lâmina 4,1-20,5 × 1,2-6 cm, oval, membranácea a cartácea, face adaxial pubescente a pilosa, face abaxial velutina, margem repanda a denteada inteira somente na base, base atenuada à decorrente frequentemente auriculada em torno do pecíolo, ápice agudo. Tirso apical de glomérulos sésseis ou subsésseis; ramos secundários ausentes, raramente presentes e paralelos ao ramo primário; bractéolas 1-11,6 mm compr. Flores sésseis, $8-18$ por glomérulo; cálice 2,8-4,2 × 1,7-3,6 mm, membranáceo, tubuloso, pubescente a velutino, lobos $1,1-2,8 \times 0,9-1,7$ $\mathrm{mm}$, agudos, face abaxial velutina, com tricomas estrelados, face adaxial glabra; corola 5,5-8,7 $\times$ 0,9-2,4 mm, tubulosa, amarela, tubo externamente pubescente à velutino e internamente piloso, lobos 0,9-2 × 0,9-2,2 mm, arredondados, face abaxial velutina, com tricomas estrelados e face adaxial glabra; estames no terço superior do tubo da corola, $0,8-1,2 \mathrm{~mm}$ compr.; ovário $1,3-3,8 \times 0,2-2,3 \mathrm{~mm}$, pubescente a velutino; estilete $2,7-5,2 \mathrm{~mm}$ compr. Frutos 4,8-5,8 × 2,4-2,8 mm. Sementes 0,6 × 0,2 $\mathrm{mm}$, piriformes.

Material selecionado: Boa Vista da Aparecida, 5.VII.1997, fl., I. Isernhagen 33 (UPCB). Curitiba, 19.VIII.2015, fl. e fr., L.C. Lannoy 04 (UPCB). Ponta Grossa, 15.VIII.1990, fl., C. Diapp 06 (UPCB). São Mateus do Sul, 20.VII.1986, fl., S.M. Silva (UPCB 14124). Telêmaco Borba, 25.IX.2015, fl. e fr., Urben-Filho 241 (UPCB).

Espécie com distribuição ampla e ocorrência na Argentina, Austrália, Bolívia, Paraguai e Uruguai (Norman 2000). No Brasil ocorre na Paraíba, Alagoas, Bahia, Distrito Federal, Goiás, Espírito Santo, Minas Gerais, Rio de Janeiro, São Paulo, Paraná, Santa Catarina e Rio Grande do Sul. No Paraná, está presente em praticamente todas as unidades de vegetação, florestais a campestres. Coletada com flores de julho a setembro e com frutos de agosto a outubro.

É a mais comumente encontrada dentre as espécies sul brasileiras. É reconhecida pela forma e tamanho das folhas, gradualmente menores em direção ao ápice da planta, tirsos com glomérulos sésseis subtendidos por folhas ou brácteas e flores amarelas. Espécie frequentemente tratada na bibliografia e em herbários identificada como Buddleja brasiliensis Jacq. ex Spreng., que é um sinônimo heterotípico (BFG 2015).

10. Buddleja thyrsoides Lam., Tabl. Encycl. 1: 291. 1791. subsp. angusticarpa E.M.Norman \& L.B.Sm., Fl. Ilustr. Catarin., Loganiáceas: 8. 1976.

Figs. 10; 2a

Arbustos eretos, dióicos, 1,5-2 m alt. Caules cilíndricos a subquadrangulares, pubescentes a velutinos variando entre ramos jovens e velhos. Folhas sésseis; estípula reduzida a uma linha; lâmina 1,9-11,2 × 1,2-2,6 cm, linear, cartácea, face adaxial glabrescente a pubescente, face abaxial pubescente à velutina, margem denteada, base atenuada, ápice agudo. Tirso apical de cimeiras ou glomérulos pedunculados; ramos secundários presentes, paralelos ao ramo primário; bractéolas 0,5-6 mm compr.; pedúnculo 1-12 $\mathrm{mm}$ compr. Flores subsésseis a pediceladas, 6-18 por cimeira ou glomérulo; pedicelo $0,6-5 \mathrm{~mm}$ compr., pubescente a velutino; cálice 1,1-2,7×1,1-2,7 mm, membranáceo, campanulado, pubescente, lobos $0,3-2,3 \times 0,4-1,5 \mathrm{~mm}$, agudos, face abaxial velutina, com tricomas estrelados, face adaxial glabra; corola 
2,6-7 $\times 1,3-3 \mathrm{~mm}$, tubulosa, creme ou branca, tubo externamente pubescente a velutino e internamente piloso, lobos 0,4-1,7 × 0,4-2,5 mm, arredondados, face abaxial e adaxial glabras; estames logo abaixo dos lobos da corola, 0,4-1,3 mm compr.; ovário $0,9-6,1 \times 0,6-2,3 \mathrm{~mm}$, pubescente a velutino; estilete $0,7-3,2 \mathrm{~mm}$ compr.; estigma capitado. Frutos 5,5-9 × 1,6-3,4 mm. Sementes 0,8-2,4 mm compr., fusiformes.

Material selecionado: Clevelândia, 22.XI.1972, fl. e fr., G. Hatschbach 30827 (MBM); 21.XI.1972, fl., G. Hatschbach 30793 (MBM). Coronel Domingo Soares, 23.IX.2013, fl., J.T. Motta 4083 (MBM). Palmas, 20.X.1966, fl. e fr., G. Hatschbach 15036 (MBM). Tijucas do Sul, 27.VII.2013, fl., M. Savarais 424 (MBM). Material adicional: BRASIL. RIO GRANDE DO SUL: Jaquirana, 11.I.2017, fr., G.P. Coelho 132 (ICN).

No Paraná, é representada apenas por Buddleja thyrsoides Lam. subsp. angusticarpa E.M.Norman \& L.B.Sm., encontrada também em Santa Catarina, Rio Grande do Sul e nos países vizinhos, Argentina, Paraguai e Uruguai. Ocorre predominantemente em área de Floresta com Araucária entremeada por Campos. Coletada com flores de julho a novembro e com frutos em outubro e novembro. É reconhecida pelas folhas estreitas e longilíneas com margem denteadas, tricomas esparsos e cálice campanulado.

\section{Agradecimentos}

Ao CNPq, as bolsas de Apoio Técnico e de Produtividade em Pesquisa concedidas à primeira e ao quarto autores, respectivamente. À CAPES, a bolsa de Mestrado concedida ao segundo e terceiro autores. Aos curadores dos herbários MBM e UPCB, a permissão para consulta aos acervos. A José Tadeu Motta e Rafael Völtz, as imagens das exsicatas.

\section{Referências}

APG II - The Angiosperm Phylogeny Group (2003) An update of the Angiosperm Phylogeny Group classification for the orders and families of flowering plants. Botanical Journal of the Linnean Society 141: 399-436.

APG IV - The Angiosperm Phylogeny Group (2016) An update of the Angiosperm Phylogeny Group classification for the orders and families of flowering plants Botanical Journal of the Linnean Society 181: 1-20.

Bentham G \& Hooker JD (1876) Loganiaceae. In: Bentham G \& Hooker JD (eds.) Genera Plantarum. Vol. 2. Excuderunt Spottiswoode et Soc., Londres. Pp. 786-789.
BFG - The Brazil Flora Group (2015) Growing knowledge: an overview of seed plant diversity in Brazil. Rodriguésia 66: 1085-1113.

Bremer B, Bremer K, Heidari N, Erixon P, Olmstead RG, Anderberg AA, Källersjo M, Barkhordarian E (2002) Phylogenetics of asterids based on 3 coding and 3 non-coding chloroplast DNA markers and the utility of non-coding DNA at higher taxonomic levels. Molecular Phylogenetics and Evolution 24: 274-301.

Chau JH, O'Leary N, Sun WB \& Olmstead RG (2017) Phylogenetic relationships in tribe Buddlejeae (Scrophulariaceae) based on multiple nuclear and plastid markers. Botanical Journal of the Linnean Society 184: 137-166.

Coelho GP (2017) O gênero Buddleja L. (Scrophulariaceae) no Brasil. Dissertação de Mestrado. Universidade Federal do Rio Grande do Sul, Porto Alegre. 185p.

CRIA (2017) Rede Species Link. Disponível em <http:// www.splink.org.br>. Acesso em 7 junho 2016.

Ferreira HD (1988) Revisão taxonômica das espécies de Buddleja L. (Buddlejaceae) que ocorrem no Brasil. Dissertação de Mestrado. Universidade Estadual de Campinas, Campinas. 111p.

Ferreira HD \& Martins SE (2005) Buddlejaceae. In: Wanderley MGL, Shepherd GJ, Melhem TS \& Giulietti AM (eds.) Flora fanerogâmica do estado de São Paulo. Instituto de Botânica, São Paulo. Vol. 4, pp. 157-161.

Fidalgo O \& Bononi VLR (1989) Técnicas de coleta, preservação e herborização de material botânico. Instituto de Botânica, São Paulo. 62p.

Gonçalves EG \& Lorenzi H (2007) Morfologia vegetal. Instituto Plantarum, São Paulo. 448p.

GOOGLE (2016) Google maps. Disponível em <http:// www.google.com.br/maps/>. Acesso em 7 junho 2016.

IPARDES - Instituto Paranaense de Desenvolvimento Econômico e Social (2016) Base Ambiental. Disponível em $<$ http://www.ipardes.gov.br/index. php?pg_conteudo $=1 \&$ cod_conteudo $=26>$. Acesso em 8 dezembro 2016.

JSTOR (2016) Global Plants. Disponível em <https:// plants.jstor.org/>. Acesso em 31 maio 2016.

Jussieu AL (1789) Genera Plantarum: secundum ordines naturales disposita, juxta methodum in Horto regio parisiense exaratum. Herissant, Paris. 498p.

Kaehler M, Goldenberg R, Labiak PH, Ribas OS, Vieira AOS \& Hatschbach GG (2014) Plantas Vasculares do Paraná. UFPR, Curitiba. 190p.

Kaehler M (2014) Scrophulariaceae. In: Kaehler M, Goldenberg R, Labiak PH, Ribas OS, Vieira AOS \& Hatschbach GG (eds.) Plantas vasculares do Paraná. UFPR, Curitiba. Pp. 182.

Labiak PH (2014) Aspectos fitogeográficos do Paraná. In: Kaehler M, Goldenberg R, Labiak PH, Ribas 
OS, Vieira AOS \& Hatschbach GG (eds.) Plantas vasculares do Paraná. UFPR, Curitiba. Pp. 7-22.

Maack R (2012) Geografia física do estado do Paraná. $4^{\mathrm{a}}$ ed. UEPG, Ponta Grossa. 526p.

Norman EM (2000) Buddlejaceae. Flora Neotropica. Monogr. 81. New York Botanical Garden, New York. 225p.

Olmstead RG \& Reeves PA (1995) Evidence for the polyphyly of the Scrophulariaceae based on chloroplast rbcL and ndhF sequences. Annals of the Missouri Botanical Garden 82: 176-193.

Olmstead RG, dePamphilis CW, Wolfe AD, Young ND, Elisons WJ \& Reeves PA (2001) Disintegration of the Scrophulariaceae. American Journal of Botany 88: 348-361.

Oxelman B, Backlund M \& Bremer B (1999) Relationships of the Buddlejaceae s. 1. Investigated using parsimony jackknife and branch support analysis of chloroplast $\mathrm{ndhF}$ and $\mathrm{rbcL}$ sequence data. Systematic Botany 24: 164-182.

Oxelman B, Kornhall P, Olmstead RG \& Bremer B (2005) Further disintegration of Scrophulariaceae. Taxon 54: 411-425.

REFLORA (2017) Herbário Virtual. Disponível em <http://reflora.jbrj.gov.br/reflora/ herbarioVirtual/>. Acesso em 31 maio 2016.
Schmidt JA (1862) Scrophularinae. In: von Martius CFP, Eichler AW \& Urban I (eds.) Flora brasiliensis. Lipsae, Munchen. Vol. 8, pars 1, pp. 230-339.

Smith LB, Guimarães EF, Pereira JF \& Norman EM (1976) Loganiáceas. In: Reitz PR (eds.) Flora Ilustrada Catarinense, Itajaí. Pp. 1-77.

Soria N (2011) Buddlejaceae. In: Ramella, L. \& Perret, P (eds.) Flora del Paraguay. Conservatoire et Jardin botaniques, Ville de Genève. Pp. 1-30.

Souza VC \& Giulietti AM (2009) Levantamento das espécies de Scrophulariaceae sensu lato nativas do Brasil. Pesquisas Botânica 60: 7-288.

Souza VC \& Lorenzi H (2012) Botânica Sistemática: guia ilustrado para identificação das famílias de fanerógamas nativas e exóticas no Brasil, baseado em APG III. $3^{\mathrm{a}}$ ed. Instituto Plantarum, Nova Odessa. 768p.

Stevens PF (2001 onwards) Angiosperm Phylogeny Website. Version 12, July 2012 (and more or less continuously updated since). Disponível em $<$ http:// www.mobot.org/MOBOT/research/APweb/>. Acesso em 21 junho 2017.

Thiers B [continuamente atualizado] Index Herbariorum: a global directory of public herbaria and associated staff. Disponível em <http://sweetgum.nybg.org/ science/ih/>. Acesso em 1 junho 2016.

\section{Lista de coletores}

Amaral-Neto LP 20 (4a). Andrade BO 65 (4a), 92 (4a). Bagliogli V 07 (9). Barbosa JM 378 (4a). Bidá A 480 (9). Botelho A s.n. MBM 70007 (9). Braga A 307 (4a). Braga R s.n. UPCB 2365 (9), s.n. UPCB 2366 (4a), 235 (9), 239 (4a), 1123 (4a). Brotto ML 1370 (4a). Carneiro J 312 (9). Carneiro JS et al. 252 (1). Cervi AC 6147 (9), 6188 (9), 9023 (9). Coelho GP 70 (6), 100 (8), 132 (10). Cordeiro J 128 (9), 134 (3), 278 (9), 1776 (4a), 1834 (3), 2141 (4a), 4653 (4a). Curial O 223 (9). Diapp C 06 (9). Dombrowski L 12685 (9), 13977 (4a). Dunaiski A 643 (4a). Dusén PKH 9354 (5), 11086 (5). Empinotte CB 10 (9). Engels ME 1292 (9), 1639 (4a). Felitto G 105 (9), 394 (4a). Hatschbach G 393 (4a), 3338 (4a), 3430 (7), 4311 (4a), 6325 (4a), 7339 (4a), 8571 (4a), 9830 (4a), 11293 (4a), 14876 (4a), 14986 (4a), 15036 (10), 15173 (6), 16425 (9), 16930 (9), 17141 (9), 17431 (2), 18052 (4a), 19779 (4b), 24427 (9), 24835 (4a), 24952 (4a), 26754 (9), 26899 (9), 27637 (4a), 29815 (9), 30724 (7), 30793 (10), 30827 (10), 32214 (9), 32221 (9), 32312 (9), 32794 (4a), 22622 (4a), 37055 (7), 38566 (4a), 40255 (9), 40453 (4a), 45455 (4a), 45734 (2), 47564 (4a), 50995 (9), 53674 (8), 59674 (4a). Hertel R s.n. MBM 221002 (9). Imaguire N s.n. MBM 171918 (9), 1003 (9), 5331 (3). Isernhagen I 33 (9). Iurk M 257. Jamhour J s.n. MBM 209639 (9). Kozera C 181 (9), 216 (4a), 3283 (4a). Kuchler RM 341 (9). Kummrow R 780 (3). Landrum LR 2308 (9). Lange RB s.n. UPCB 2270 (9), s.n. UPCB 2271 (4a), 98 (9), 147 (4a). Lannoy LC 01 (4a), 03 (9), 04 (9), 05 (9), 06 (9). Lima R 08 (9). Lindeman J 2505 (4a), 3052 (4a). Lisingen 81 (9). Lozano ED 437 (4a), 1578 (4a). Martins AC 11 (4a). Mattos J 11893 (4a), 14037 (4a), 14346 (4a). Meijer A 1979 (9). Melo E 296 (9). Miranda AC 205 (9). Moreira EA 50 (4a). Motta JT 79 (9), 4042 (4a), 4083 (10). Oliveira PI 276 (4a). Possete RFS 395 (9), 374 (9). Rambo B s.n. HUCS 6726 (2). Reginato M 485 (9). Ribas OS 164 (4a), 567 (4a), 7867 (9), 1963 (9). Sakagami CR s.n. UPCB 50265 (9). Santos CB s.n. UPCB 40310 (9). Santos EP 339 (4a). Savarais M 375 (9), 424 (10). Silva EM 7300 (6). Silva JM 2595 (4a), 3800 (4a), 8632 (4a). Silva MG 03 (9). Silva SM et al. s.n. MBM 121618 (9), 1675 (4a). Snak C 230 (4a). Souza LP 123 (4a), 191 (4a). Souza MKF s.n. UPCB 43251 (4a). Svolenski AC 241 (9). Tessmann G s.n. UPCB 1221 (4a), 2744 (4a). Tomé MVF 962 (9), 969 (9), 982 (9). Uchibaba EY s.n. MBM 140054 (9). UrbenFilho A 241 (9). Völtz RR 54 (4a). Ziller SR 272.

Editora de área: Dra. Marli Morim Artigo recebido em 10/05/2017. Aceito para publicação em 26/07/2017. This is an open-access article distributed under the terms of the Creative Commons Attribution License. 